\title{
Efficacy of continuous in-wound infusion of levobupivacaine and ketorolac for post- caesarean section analgesia: a prospective, randomised, double-blind, placebo- controlled trial
}

\author{
Jozica Wagner-Kovacec ${ }^{1 *}$ (D, Petra Povalej-Brzan ${ }^{2,3,4}$ and Dusan Mekis ${ }^{1,2,3,5}$
}

\begin{abstract}
Background: In-wound catheters for infusion of local anaesthetic for post-caesarean section analgesia are well tolerated in parturients. Few studies have examined continuous in-wound infusion of a combination of local anaesthetic and non-steroidal anti-inflammatory drug for post-caesarean section analgesia. This single centre study evaluated post-operative analgesic efficacy and piritramide-sparing effects of continuous in-wound infusion of either local anaesthetic or non-steroidal anti-inflammatory agent, or the combination of both, versus saline placebo, when added to systemic analgesia with paracetamol.
\end{abstract}

Methods: After National Ethical Board approval, 59 pregnant women scheduled for non-emergency caesarean section were included in this prospective, randomised, double-blind, placebo-controlled study. The parturients received spinal anaesthesia with levobupivacaine and fentanyl. Post-operative analgesia to $48 \mathrm{~h}$ included paracetamol $1000 \mathrm{mg}$ intravenously every $6 \mathrm{~h}$, with the studied agents as in-wound infusions. Rescue analgesia with piritramide was available as needed, titrated to $2 \mathrm{mg}$ intravenously. Four groups were compared, using a subcutaneous multiholed catheter connected to an elastomeric pump running at $5 \mathrm{~mL} / \mathrm{h}$ over $48 \mathrm{~h}$. The different in-wound infusions were: levobupivacaine $0.25 \%$ alone; ketorolac tromethamine $0.08 \%$ alone; levobupivacaine $0.25 \%$ plus ketorolac tromethamine $0.08 \%$; or saline placebo. The primary outcome was total rescue piritramide used at $24 \mathrm{~h}$ and $48 \mathrm{~h}$ post-operatively, under maintained optimal post-caesarean section analgesia.

Results: Compared to placebo in-wound infusions, ketorolac alone and levobupivacaine plus ketorolac in-wound infusions both significantly reduced post-operative piritramide consumption at $24 \mathrm{~h}$ ( $p=0.003 ; p<0.001$, respectively) and $48 \mathrm{~h}(p=0.001 ; p<0.001)$. Compared to levobupivacaine, levobupivacaine plus ketorolac significantly reduced post-operative piritramide consumption at $24 \mathrm{~h}(p=0.015)$ and $48 \mathrm{~h}(p=0.021)$. For levobupivacaine versus ketorolac, no significant differences were seen for post-operative piritramide consumption at $24 \mathrm{~h}$ and $48 \mathrm{~h}(p=0.141 ; p=0.054)$. Conclusion: Continuous in-wound infusion with levobupivacaine plus ketorolac provides greater opioid-sparing effects than continuous in-wound infusion with levobupivacaine alone.

Trial registration: German Clinical Trials Register: retrospectively registered on 30 July, 2014, DRKS 00006559.

Keywords: Caesarean section, Analgesia, In-wound infusion, Levobupivacaine, Ketorolac

\footnotetext{
* Correspondence: jozica.wagner-kovacec@guest.arnes.si

The study was partially presented as an abstract at Obstetric Anaesthesia Brussels: A European Congress, 18-19 May, 2017.

'Department of Anaesthesiology, Intensive Care and Pain Management,

University Medical Centre Maribor, Ljubljanska ulica 5, 2000 Maribor, Slovenia

Full list of author information is available at the end of the article
}

(c) The Author(s). 2018 Open Access This article is distributed under the terms of the Creative Commons Attribution 4.0 International License (http://creativecommons.org/licenses/by/4.0/), which permits unrestricted use, distribution, and reproduction in any medium, provided you give appropriate credit to the original author(s) and the source, provide a link to the Creative Commons license, and indicate if changes were made. The Creative Commons Public Domain Dedication waiver (http://creativecommons.org/publicdomain/zero/1.0/) applies to the data made available in this article, unless otherwise stated. 


\section{Background}

Caesarean section is a common surgical procedure that is being performed at increasingly higher rates $[1,2]$. Immediate post-operative pain can be higher than for many other types of major surgery [3]. Effective pain relief after caesarean section is very important, as it allows the mother to take care of her new-born baby. Suboptimally treated or persistent post-operative pain can lead to impaired physical function and loss of sleep, and is associated with premature arrest of breastfeeding, inability to care for the new-born, thromboembolism due to delayed ambulation, delayed discharge, parturient dissatisfaction, persistent pain, and postnatal depression $[4,5]$. The incidence of persistent pain after caesarean section is $6 \%$ to $18 \%$ [6], although a recent study showed a low incidence of persistent pain (0.3\%) at 12 months after child-birth [7].

The incidence of post-operative pain remains high despite the availability of new drugs and novel analgesic techniques [3], potentially due to the worries about side-effects of the analgesic on the mother and the new-born through analgesic secretion in the breast milk [3]. Inter-individual variations in pain perception also complicate the effectiveness of post-caesarean section analgesia [8, 9]. Pre-operative predictive tests for postcaesarean pain have been studied and might provide the basis for individualised approaches to multimodal post-operative pain management $[10,11]$. As adjuncts to neuraxial and systemic analgesics, regional nerve blockade and wound infiltration have been recommended as components of multimodal analgesia for post-caesarean pain relief [12].

The aim of the present study was to evaluate the effectiveness of pain treatment with in-wound infusion of levobupivacaine and/or ketorolac after caesarean section as adjuvant to systemic analgesics. The primary outcome was total rescue piritramide used at $24 \mathrm{~h}$ and $48 \mathrm{~h}$ post-operatively. Secondary aims were persistent post-operative pain and/or any new skin sensation after 8 weeks, and satisfaction of the parturient with the quality of analgesia.

\section{Methods}

This prospective, randomised, double-blind, placebocontrolled trial was approved by the National Medical Ethics Committee (Republic of Slovenia National Medical Ethics Committee, Number 169/07/11) on 12 July, 2011, and is registered with the German Clinical Trials Registry (DRKS 00006559). Pregnant women scheduled for non-emergency caesarean section were recruited at University Clinical Centre Maribor, Slovenia, from January 2012 to September 2014. All of the participants gave their written informed consent.

The inclusion criteria were: age $\geq 18$ years; gestational age $\geq 37$ weeks; and American Society of Anesthesiologists (ASA) physical status I or II. The exclusion criteria included: refusal to participate; ASA III or higher; previous caesarean section or abdominal surgery; body mass index $>30 \mathrm{~kg} / \mathrm{m}^{2}$ before conception; history of drug or alcohol abuse; allergies to local anaesthetics, paracetamol or non-steroidal anti-inflammatory drugs (NSAIDs); and any known contra-indication for neuraxial anaesthesia.

The parturients were seen during the pre-operative visit by the research personnel, evaluated for study inclusion, and approached for recruitment and informed consent. They were instructed regarding the study group allocation, the analgesia system they would use after surgery, the continuous in-wound infusion device, how to use numeric rating scales (NRS), from 0 to 10 for pain ( 0 , none, to 10 , worst possible pain), and from 1 to 5 for quality of analgesia. They were also introduced to the persistent post-operative pain questionnaire.

All of the parturients were premedicated with ranitidine $50 \mathrm{mg}$ intravenously (i.v.) and metoclopramide $10 \mathrm{mg}$ i.v., and $30 \mathrm{~mL}$ oral $0.3 \mathrm{M}$ sodium citrate. After a $250 \mathrm{~mL}$ i.v. preload with 6\% hydroxyethyl starch 130/0.4 in $0.9 \%$ sodium chloride (saline), the parturients were monitored using standard intra-operative monitoring (i.e., non-invasive blood pressure, electrocardiogram, peripheral oxygen saturation pressure $\left.\left[\mathrm{SpO}_{2}\right]\right)$. A standardised intrathecal anaesthesia injection was performed for all parturients. With the parturient in the sitting position, a 25-gauge pencil-point spinal needle was inserted in the $\mathrm{L}_{3}-\mathrm{L}_{4}$ interspace, and $2.0 \mathrm{~mL}$ to $2.2 \mathrm{~mL}$ levobupivacaine $0.5 \%$ with fentanyl $15 \mu \mathrm{g}$ was injected. The parturients were positioned supine, with $15^{\circ}$ to $30^{\circ}$ left tilt, for prevention of possible aorto-caval compression. A bladder catheter was inserted just before the sensory block reached the $\mathrm{T}_{4-6}$ level.

The parturients were randomly allocated to one of the four groups before surgery, according to numbered sealed envelopes. The sealed envelopes were chosen by the parturients and given to the nurse anaesthetists, who prepared an elastomeric pump (On Q Pain Buster; I-Flow Corporation, Lake Forest, CA, USA) in the operating theatre next door. The elastomeric pump was filled with $270 \mathrm{~mL}$ of the study solution indicated on each paper in the envelopes, and run at $5 \mathrm{~mL} / \mathrm{h}$. The four groups received continuous post-operative infusions of saline with the following additions: levobupivacaine $0.25 \%$ alone (LB group); ketorolac tromethamine $0.08 \%$ alone (KT group); levobupivacaine $0.25 \%$ plus ketorolac tromethamine $0.08 \%(\mathrm{LB}+\mathrm{KT})$; saline placebo.

Here, levobupivacaine was selected as the local anaesthetic for its low toxicity and analgesic potency, with levobupivacaine $0.25 \%$ in continuous in-wound infusion not expected to give any problems of overdosing for the average weight of the parturients. Ketorolac was selected as the NSAID as it is safe and effective for post-caesarean i.v. pain therapy, and safe regarding breastfeeding. The maximal 
daily i.v. dose of ketorolac should also be safe for subcutaneous infusion.

If the systolic blood pressure of the parturients was $<90 \mathrm{mmHg}$ or if they showed nausea and/or vomiting due to hypotension, phenylephrine $50 \mu \mathrm{g}$ to $100 \mu \mathrm{g}$ or ephedrine $5 \mathrm{mg}$ to $10 \mathrm{mg}$ was titrated i.v. until the parturient regained their normal blood pressure. For nausea or vomiting, ondansetron $4 \mathrm{mg}$ was given i.v..

After local subcutaneous infiltration with $20 \mathrm{~mL}$ of one of the randomised agents, the skin was closed with a multi-holed $12.5-\mathrm{cm}$ catheter inserted into the wound above the fascia. Continuous infusion of the randomised agent was then started, at $5 \mathrm{~mL} / \mathrm{h}$ (using an elastomeric pump), and continued for $48 \mathrm{~h}$. The parturient and the staff involved in the peri-operative management and data collection were blinded to the assignment of the parturient to one of the four randomised agents.

The post-operative analgesia protocol to $48 \mathrm{~h}$ included paracetamol $1000 \mathrm{mg}$ i.v. every $6 \mathrm{~h}$, along with the studied agents as in-wound infusions. For rescue analgesia, piritramide was available as needed, titrated to $2 \mathrm{mg}$ i.v. until a pain NRS $\leq 4$.

The demographic characteristics and gestational ages were collected for the parturients. Over the first $48 \mathrm{~h}$ post-caesarean section, the pain NRS (0-10) was completed (at 3, 6, 12, 18, 24, 36 and $48 \mathrm{~h}$ ) as specified for the pain at the surgical site at rest and under movement (e.g., raising legs, coughing, walking), for nausea and/or vomiting (yes/no), and for any new skin sensations at the surgical site (yes/no). The time from the end of the operation to the first request for piritramide was recorded. After $72 \mathrm{~h}$, the satisfaction of the parturient for the quality of analgesia for the first $48 \mathrm{~h}$ after the caesarean section was determined (NRS 1-5; 1, very bad; 2, bad; 3, good; 4 , very good; 5 , excellent). After 8 weeks, the parturients were contacted by telephone for completion of a questionnaire about any persistent post-operative pain (Table 1).

The primary outcome was total rescue piritramide used at $24 \mathrm{~h}$ and $48 \mathrm{~h}$ post-operatively. Secondary aims were persistent post-operative pain and/or any new skin sensation after 8 weeks, and the satisfaction of the parturient with the quality of analgesia.

\section{Statistical analysis}

The required sample size calculation was based on a pilot study of 20 parturients (five for each group). The calculated maximum number of required parturients for each group was 19 to satisfy $80 \%$ power of detecting an effect of medium size (0.4) and an $\alpha$ error probability of 0.05 . According to this sample size calculation, we planned to enrol 88 participants.

Statistical analysis was performed using SPSS V. 24.0 (IBM). The parturient demographic and parametric data were analysed using ANOVA, with Bonferroni post-hoc
Table 1 Questionnaire used for persistent post-operative pain

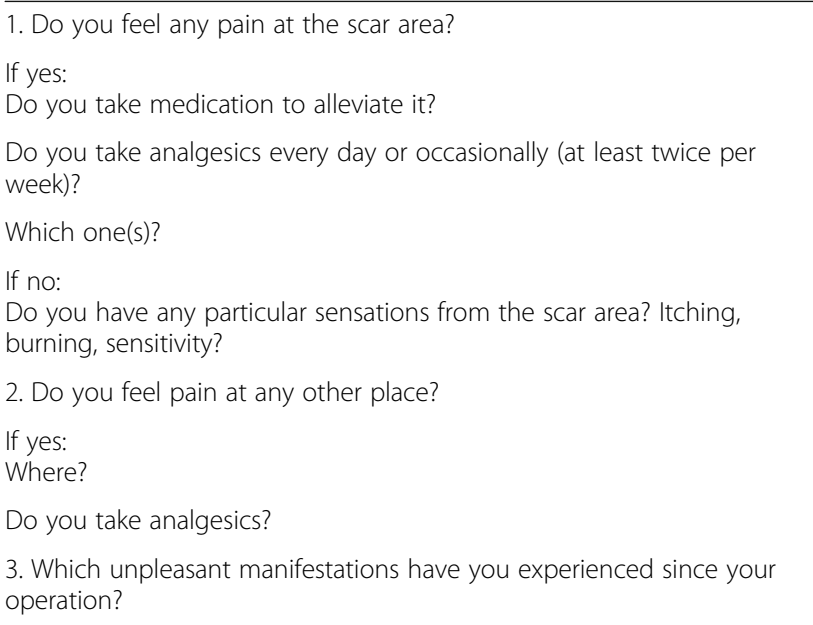

tests for correction for multiple comparisons. The non-parametric data for the between-group comparisons were analysed using Kruskal Wallis tests and post-hoc tests with Bonferroni correction. Chi-square tests were performed to determine the differences among groups for the feeling of persistent pain and for any new skin sensations. Parametric data are presented as means \pm standard deviation (SD), and non-parametric data are presented as medians and 95\% confidence interval (CI). $p<0.05$ was considered significant.

\section{Results}

Fifty-nine participants completed the study and were included in the data analysis. The Consolidated Standards of Reporting Trials (CONSORT) diagram is shown in Fig. 1, and the parturient characteristics are given in Table 2. The groups were compared using Kruskal Wallis tests. Between group comparisons were made using Bonferroni correction. Across the parturient characteristics (i.e., age, weight, height, body mass index, gestational age), there was a significant difference for age $(p=0.014)$ and gestational age $(p=0.012)$ across all of the treatment groups. The between groups analysis showed that the LB group had significantly lower age and gestational age compared to the placebo group. The other groups did not show any significantly differences in these observed characteristics (Table 2).

The total consumption of piritramide for 12,24 and $48 \mathrm{~h}$ across the four groups is given in Table 3, with the median and interquartile ranges for the total consumption of piritramide shown in Fig. 2. Two of the parturients in the KT group and six from the $\mathrm{LB}+\mathrm{KT}$ group did not request any piritramide in the first $24 \mathrm{~h}$ post-caesarean section. One parturient from the KT group and five from the LB $+\mathrm{KT}$ group did not request any piritramide to $48 \mathrm{~h}$ post-caesarean section.

There were significant differences in the total consumption of piritramide at $24 \mathrm{~h}$ post-caesarian section 


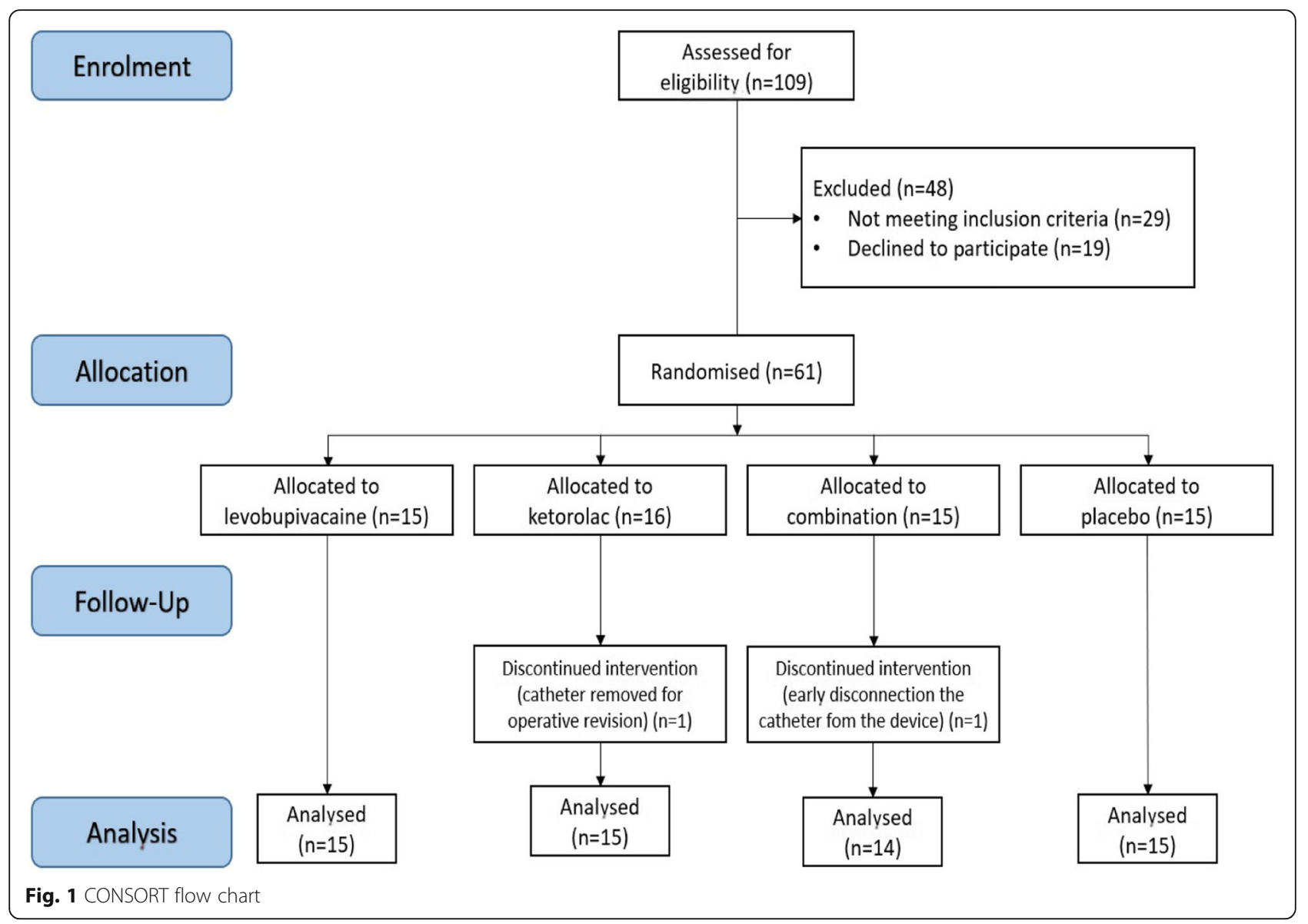

between the groups of KT versus placebo $(p=0.003)$, LB $+\mathrm{KT}$ versus placebo $(p<0.001)$ and $\mathrm{LB}$ versus $\mathrm{LB}+\mathrm{KT}$ $(p=0.015)$. However, there were no significant differences in the total consumption of piritramide at $24 \mathrm{~h}$ between the other groups, as LB versus placebo $(p=1.00)$, $\mathrm{KT}$ versus $\mathrm{LB}+\mathrm{KT}(p=1.000)$ and LB versus KT $(p=$ $0.141)$. Similarly, there were significant differences in the total consumption of piritramide at $48 \mathrm{~h}$ between the groups of $\mathrm{KT}$ versus placebo $(p=0.001), \mathrm{LB}+\mathrm{KT}$ versus placebo $(p<0.001)$ and LB versus LB + KT $(p=0.021)$. There were no significant differences in the total consumption of piritramide at $48 \mathrm{~h}$ between the other groups, as LB versus placebo $(p=1.000)$, KT versus LB + $\mathrm{KT}(p=1.000)$ and LB versus KT $(p=0.054)$.

Table 2 Parturient characteristics across the four parturient groups

\begin{tabular}{|c|c|c|c|c|c|}
\hline Characteristic & $\begin{array}{l}\text { Levobupivacaine } \\
\text { alone }(n=15)\end{array}$ & $\begin{array}{l}\text { Ketorolac tromethamine } \\
\text { alone }(n=15)\end{array}$ & $\begin{array}{l}\text { Combination } \\
(n=14)\end{array}$ & $\begin{array}{l}\text { Saline placebo } \\
(n=15)\end{array}$ & $p$-value \\
\hline Age (years) & $28.1 \pm 2.92^{\mathrm{a}}$ & $31.7 \pm 5.11$ & $28.8 \pm 5.01$ & $32.5 \pm 3.91^{a}$ & $\begin{array}{l}0.014^{\mathrm{a}} \text { (levobupivacaine vs } \\
\text { saline placebo) }\end{array}$ \\
\hline Weight at conception (kg) & $62.0 \pm 10.71$ & $59.4 \pm 6.81$ & $64.0 \pm 8.56$ & $64.1 \pm 5.74$ & ns \\
\hline Weight at caesarean section (kg) & $74.9 \pm 11.50$ & $74.7 \pm 9.18$ & $80.2 \pm 8.93$ & $79.0 \pm 7.60$ & ns \\
\hline Height (cm) & $167.5 \pm 6.06$ & $166.1 \pm 4.91$ & $166.5 \pm 5.97$ & $165.9 \pm 4.22$ & ns \\
\hline $\begin{array}{l}\text { Body mass index at conception } \\
\left(\mathrm{kg} / \mathrm{m}^{2}\right)\end{array}$ & $21.9 \pm 3.42$ & $21.2 \pm 2.34$ & $22.8 \pm 2.46$ & $23.1 \pm 2.34$ & ns \\
\hline $\begin{array}{l}\text { Body mass index at caesarean } \\
\text { section }\left(\mathrm{kg} / \mathrm{m}^{2}\right)\end{array}$ & $26.7 \pm 3.78$ & $27.1 \pm 3.09$ & $28.9 \pm 2.27$ & $28.7 \pm 3.20$ & ns \\
\hline Gestational age (weeks) & $386 / 7 \pm 0.71^{a}$ & $386 / 7 \pm 0.80$ & $385 / 7 \pm 0.67$ & $392 / 7 \pm 0.71^{a}$ & $\begin{array}{l}0.012^{\mathrm{a}} \text { (levobupivacaine vs } \\
\text { saline placebo) }\end{array}$ \\
\hline
\end{tabular}


Table 3 Total consumption of piritramide across the four parturient groups, at 12, 24 and $48 \mathrm{~h}$

\begin{tabular}{|c|c|c|c|c|c|c|}
\hline \multirow[t]{2}{*}{ Parturient group } & \multirow{2}{*}{$\begin{array}{l}\text { Time } \\
\text { (h) }\end{array}$} & \multicolumn{4}{|c|}{ Total consumption of piritramide (mg) } & \multirow[t]{2}{*}{$p$-value } \\
\hline & & Median & Minimum & Maximum & $95 \% \mathrm{Cl}$ & \\
\hline \multirow[t]{3}{*}{ Levobupivacaine alone } & 12 & 8 & 0 & 16 & $8-14$ & ns \\
\hline & 24 & 10 & 0 & 34 & $8-14$ & $0.015^{\mathrm{a}}$ (vs combination) \\
\hline & 48 & 14 & 0 & 34 & $8-22$ & $0.021^{\mathrm{a}}$ (vs combination) \\
\hline \multirow[t]{3}{*}{ Ketorolac tromethamine alone } & 12 & 4 & 0 & 16 & $2-10$ & ns \\
\hline & 24 & 4 & 0 & 18 & $4-16$ & $0.003^{\mathrm{a}}$ (vs saline placebo) \\
\hline & 48 & 4 & 0 & 20 & $4-16$ & $0.001^{\mathrm{a}}$ (vs saline placebo) \\
\hline \multirow[t]{3}{*}{ Combination } & 12 & 2 & 0 & 10 & $2-6$ & ns \\
\hline & 24 & 2 & 0 & 14 & $0-8$ & $\begin{array}{l}<0.001^{\mathrm{a}} \text { (vs saline placebo) } \\
0.015^{\mathrm{a}} \text { (vs levobupivacaine) }\end{array}$ \\
\hline & 48 & 4 & 0 & 18 & $2-10$ & $\begin{array}{l}<0.001^{\mathrm{a}} \text { (vs saline placebo) } \\
0.021^{\mathrm{a}} \text { (vs levobupivacaine) }\end{array}$ \\
\hline \multirow[t]{3}{*}{ Saline placebo } & 12 & 10 & 4 & 38 & $6-16$ & ns \\
\hline & 24 & 16 & 6 & 50 & $10-22$ & $\begin{array}{l}0.003^{\mathrm{a}} \text { (vs ketorolac tromethamine) } \\
<0.001^{\mathrm{a}} \text { (vs combination) }\end{array}$ \\
\hline & 48 & 24 & 8 & 76 & $16-30$ & $\begin{array}{l}0.001^{\mathrm{a}} \text { (vs ketorolac tromethamine) } \\
<0.001^{\mathrm{a}} \text { (vs combination) }\end{array}$ \\
\hline
\end{tabular}

Cl confidence interval

${ }^{a}$ significant difference among groups calculated using ANOVA/ Kruskal Wallis tests, and between groups comparison post-hoc tests with Bonferroni correction; ns, non-significant

The data collected for the pain NRS for the seven time points (i.e., 3, 6, 12, 18, 24, 36, 48 h) at rest and under movement are shown in Figs. 3 and 4, respectively. There were significant differences for pain NRS at rest between the groups: after $3 \mathrm{~h}$ as LB $+\mathrm{KT}$ versus placebo $(p=0.006)$; after $12 \mathrm{~h}$ as $\mathrm{LB}+\mathrm{KT}$ versus placebo $(p=0.015)$, and LB versus LB $+\mathrm{KT} \quad(p=$ $0.046)$; after $24 \mathrm{~h}$ as $\mathrm{KT}$ versus placebo $(p=0.005)$, $\mathrm{LB}+\mathrm{KT}$ versus placebo $(p=0.041)$, and LB versus $\mathrm{KT}$ $(p=0.035)$; and after $36 \mathrm{~h}$ as $\mathrm{KT}$ versus placebo $(p=$ 0.013). There were no significant differences for pain NRS at rest for any of the other comparisons (Fig. 3).

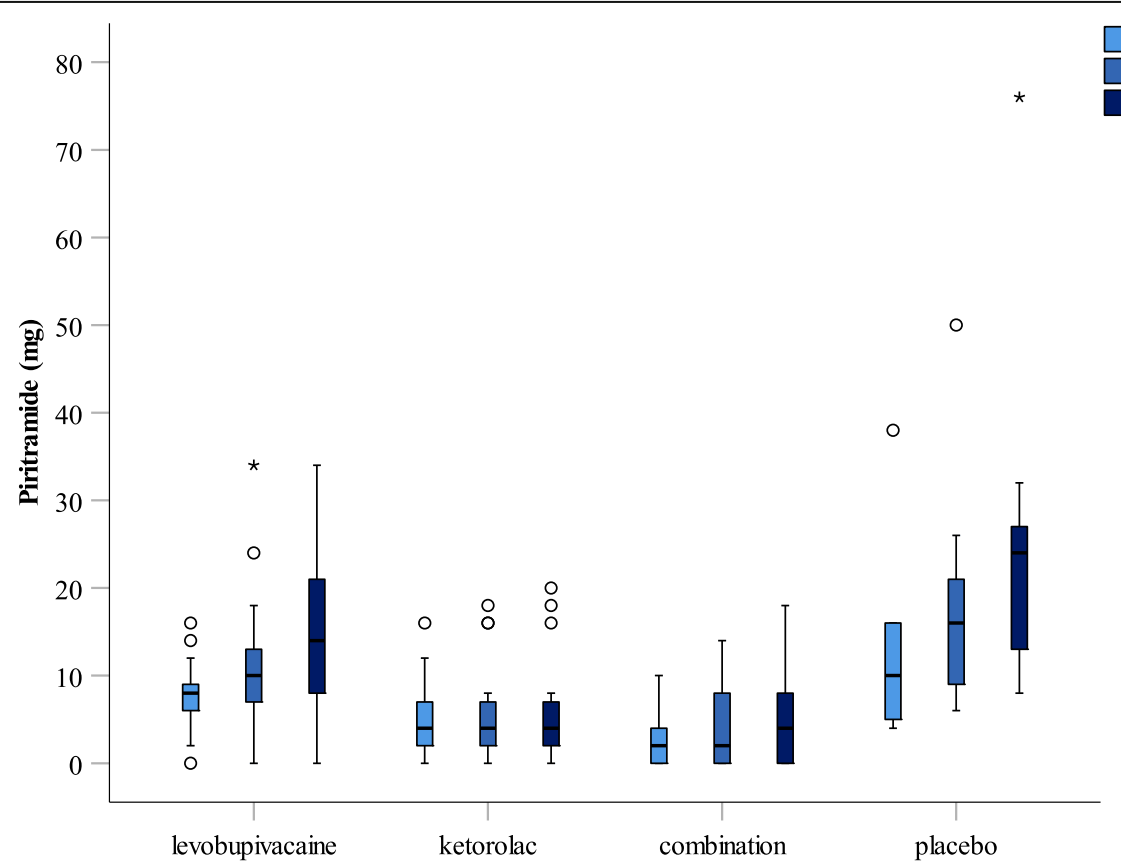

Fig. 2 Medians and interquartile ranges across the four parturient groups for the total consumption of piritramide, at 12, 24 and $48 \mathrm{~h}$ post-caesarean section. ${ }^{*}$, outliers 


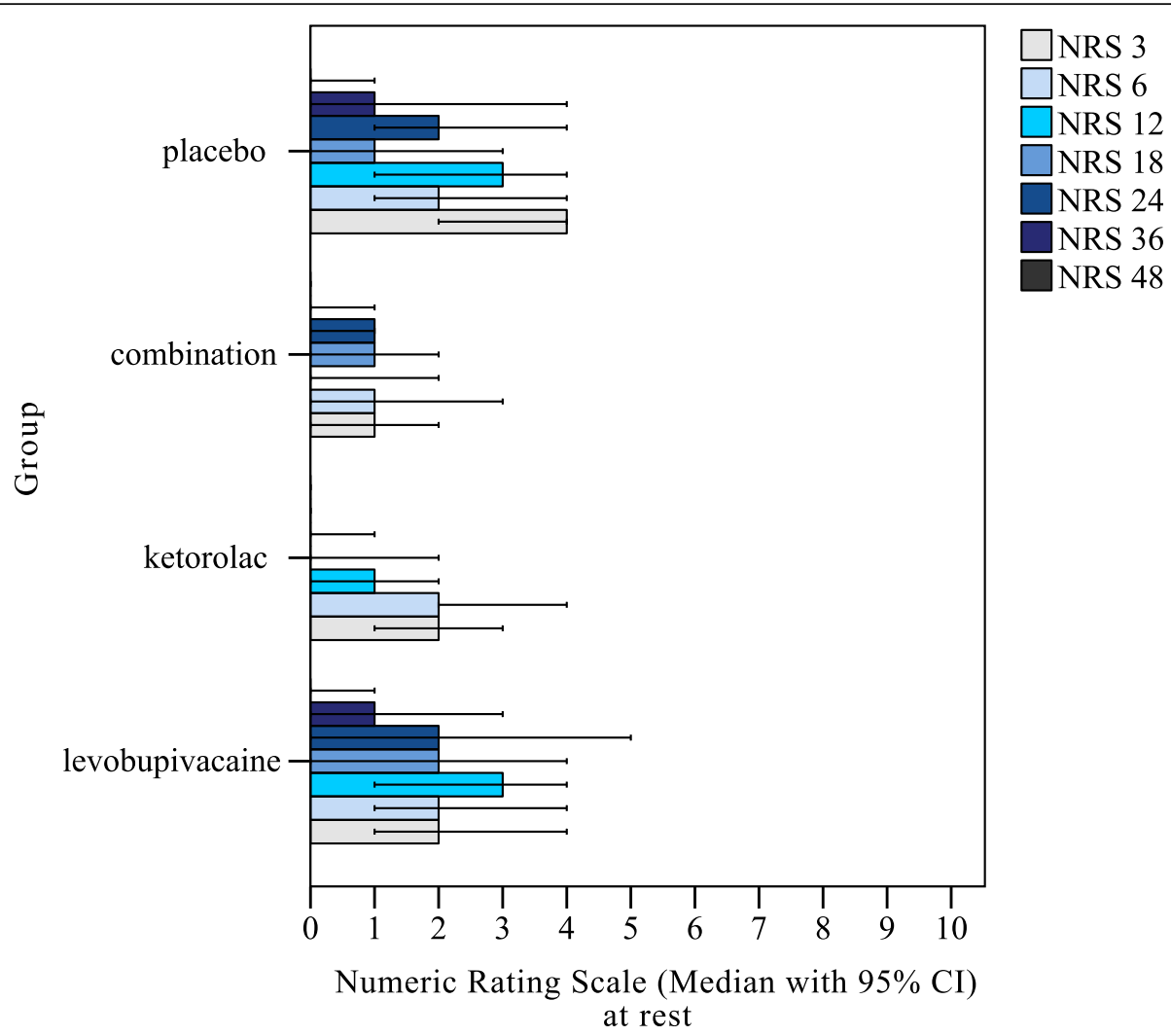

Fig. 3 Medians and interquartile ranges across the four parturient groups for the NRS for pain at rest, at 3, 6, 12, 18, 24, 36 and $48 \mathrm{~h}$ post-caesarean section. ${ }^{*}$, outliers

There were also significant differences for pain NRS under movement between the groups: after $24 \mathrm{~h}$ as $\mathrm{KT}$ versus placebo $(p=0.025)$, and $\mathrm{LB}+\mathrm{KT}$ versus placebo $(p=0.003)$; after $36 \mathrm{~h}$ as $\mathrm{LB}+\mathrm{KT}$ versus placebo $(p=0.018)$, and LB versus LB $+\mathrm{KT}(p=0.029)$ (Fig. 4).

The recorded times from the end of the caesarean section to the first request for piritramide, for persistent post-operative pain (after 8 weeks), for any new skin sensations at the operative site (after 8 weeks), and for parturient satisfaction with the quality of their analgesia over the first $48 \mathrm{~h}$ post-caesarean section (after $72 \mathrm{~h}$ ), are presented in Table 4. Persistent pain was reported by one parturient $(7.1 \%)$ in the LB group and one parturient $(7.1 \%)$ in the KT group. No parturients complained about persistent pain in the $\mathrm{LB}+\mathrm{KT}$ group or in the placebo group. The feeling of new sensation was significantly different among the groups $(p=0.026)$. The most common new sensation was for the placebo group (60\%), and the least common for the LB + KT group (7.1\%). The quality of analgesia over $48 \mathrm{~h}$ post-operative time was assessed $72 \mathrm{~h}$ post-caesarean section. Parturients in the LB + KT group defined their analgesia as excellent, and in the placebo group as very good $(p=0.005)$.

\section{Discussion}

This study compared the effectiveness of pain treatments with in-wound infusion of levobupivacaine and/or ketorolac and placebo after caesarean section. These data show more effective post-caesarean analgesia when ketorolac or the combination of levobupivacaine with ketorolac were used for the in-wound infusion. Furthermore, these data show that two parturients from the KT group and six from the LB + KT group did not need any piritramide in the first $24 \mathrm{~h}$ post-caesarean section, while one parturient from the KT group and five from the LB + KT group did not need any piritramide by $48 \mathrm{~h}$ post-caesarean section.

Local anaesthetics have an important role in post-operative analgesia, and they might have a role in the prevention of persistent pain after caesarean section [13, 14]. Some previous trials have provided evidence of analgesia benefits from adding NSAIDs to local anaesthetics for continuous in-wound infusion. Carvalho et al. showed that when low-dose ketorolac, but not hydromorphone, was added to 48-h continuous bupivacaine in-wound infusion, this significantly improved analgesia after caesarean section. Ketorolac reduced pain scores and the need for analgesia, and also reduced the inflammatory cytokines in the wound exudate (i.e., interleukines 6 and 10) [15]. 


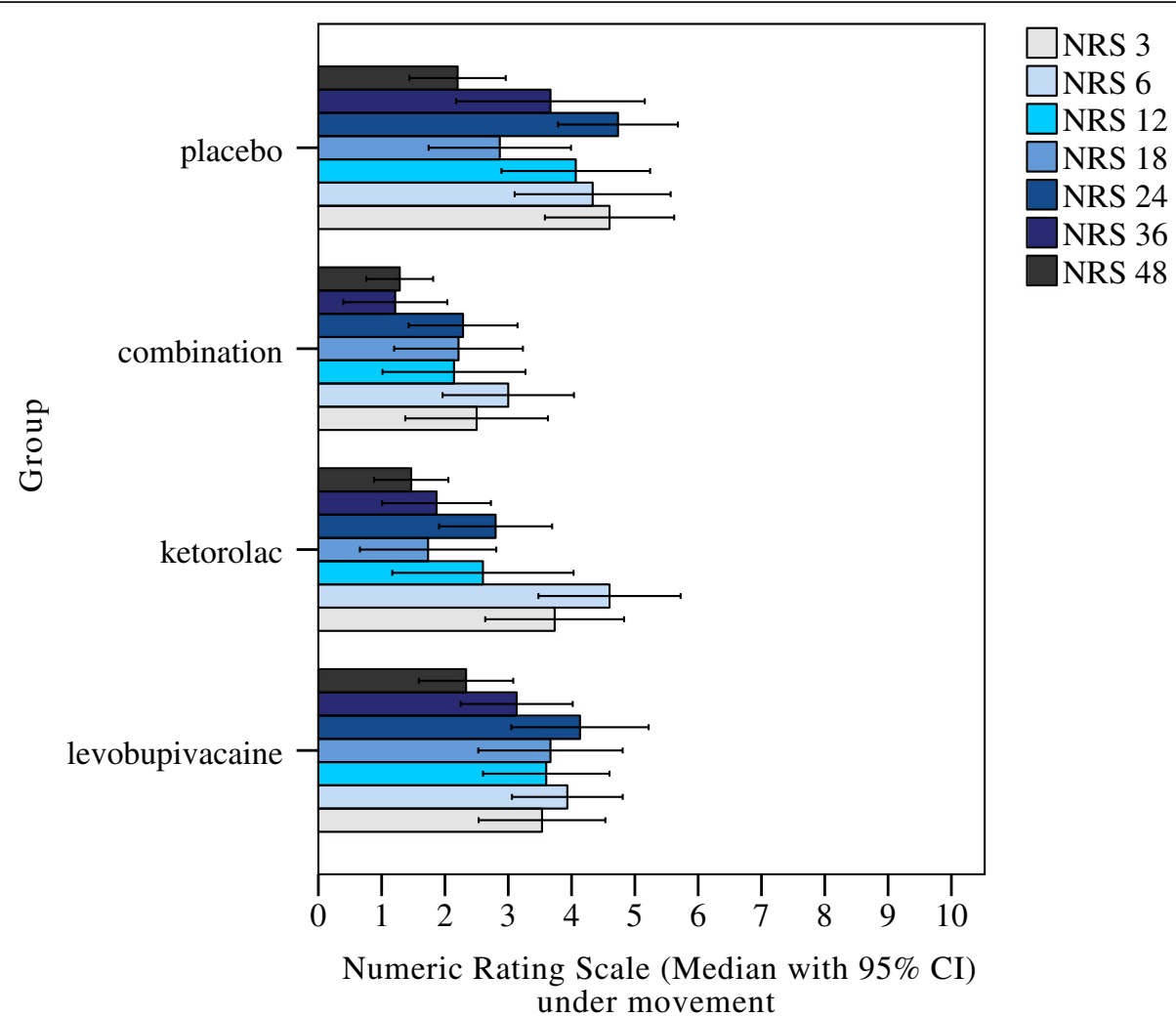

Fig. 4 Medians and interquartile ranges across the four parturient groups for the NRS for pain under movement, at 3, 6, 12, 18, 24, 36 and $48 \mathrm{~h}$ post-caesarean section. *, outliers

Lavand'homme et al. investigated continuous in-wound infusion of diclofenac for post-caesarean section analgesia, as compared to ropivacaine and placebo, and combined with systemic diclofenac therapy. They reported that local infusion of diclofenac significantly reduced post-operative morphine consumption in comparison with saline infusion and systemic diclofenac, without any specific adverse effects. Thus, post-operative analgesia produced by local diclofenac infusion was as effective as local ropivacaine infusion with systemic diclofenac [16].
Rackelboom et al. evaluated the significance of the anatomical layer (i.e., above the fascia, below the fascia) for continuous in-wound infusion of ropivacaine combined with ketoprofene, using a multiorifice catheter. They showed that infusion below the fascia significantly reduced both pain at rest and total post-operative morphine consumption, compared with infusion above the fascia [17].

However, some studies have reported no specific advantages of continuous infusion of local anaesthetics below the fascia [18], while others have reported that

Table 4 Pain-associated data across the four parturient groups

\begin{tabular}{|c|c|c|c|c|}
\hline Parturient group & $\begin{array}{l}\text { Time to first piritramide } \\
\text { request [min }(95 \% \mathrm{Cl})]\end{array}$ & $\begin{array}{l}\text { Persistent post-operative pain } \\
\text { (8 weeks; yes/no) [n (\%)] }\end{array}$ & $\begin{array}{l}\text { New skin sensation (8 weeks; } \\
\text { yes/no) [n (\%)] }\end{array}$ & $\begin{array}{l}\text { Quality of analgesia } \\
\text { (48 h; NRS 1-5) }\end{array}$ \\
\hline Levobupivacaine & $163(120-250)$ & $1(7.1)$ & $7(46.7)$ & $4(4-5)$ \\
\hline Ketorolac tromethamine & $180(160-465)$ & $1(7.1)$ & $5(35.7)$ & $4(4-5)$ \\
\hline Combination & $295(125-475)$ & $0(0)$ & $1(7.1)^{\mathrm{a}}$ & $5(5-5)^{\mathrm{a}}$ \\
\hline Saline placebo & $160(120-185)$ & $0(0)$ & $9(60.0)^{a}$ & $4(4-5)^{a}$ \\
\hline$p$-value & ns & $* *$ & 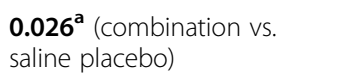 & 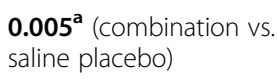 \\
\hline
\end{tabular}

Cl confidence interval

${ }^{a}$ significant difference among groups calculated using ANOVA/ Kruskal Wallis tests, and between groups comparison post-hoc tests with Bonferroni correction; ${ }^{* *} p$ value could not be calculated due to zero positive cases in some groups; ns, non-significant; NRS $1-5$, numeric rating scale for quality of analgesia from 1 to 5 ; significant differences are marked with bold text 
subfascial continuous in-wound infusion of local anaesthetics for post-operative analgesia is as effective as intrathecal morphine [19, 20], or even more effective than epidural morphine [21]. O'Neil et al. reported that their ropivacaine continuous in-wound infusion group achieved better analgesia than their epidural morphine group, with significantly lower side effects and less staff workload [21]. Kainu et al. reported that continuous in-wound infusion with ropivacaine or saline for $48 \mathrm{~h}$ was less effective than intrathecal morphine, with no difference between the local anaesthetic and placebo groups [18]. Their findings support our results, with no significant difference in analgesic efficacy between levobupivacaine and placebo.

Adesope et al. provided a systematic review and meta-analysis of 21 studies on local anaesthetics for in-wound infiltration for post-caesarean analgesia. They reported reduced pain scores at rest and under movement and significant reduction in opioid consumption at 24 h with catheter placement below the fascia, as opposed to above the fascia [22]. Our data are not in agreement here comparing the anatomical placement of the catheter, where we used an NSAID in combination with the local anaesthetic.

There are some concerns about continuous subcutaneous infusion of ketorolac. There have been no studies on ketorolac pharmacokinetics after subcutaneous infusion in pregnant or postpartum women. This will probably be slightly different from healthy volunteers. However, there is some evidence of this use in cancer patients and healthy volunteers, and it appears to be safe $[23,24]$. In the present study, the maximal allowed daily doses for i.v. therapy for post-caesarean section analgesia were used, on the assumption that subcutaneous infusion would be as safe as i.v. therapy. Subcutaneous infusion has been reported to result in lower high-peak plasma levels in healthy volunteers, and as such, this administration of ketorolac might have fewer side-effects [24].

There are a number of limitations to this study. The primary outcome of the study was total amount of rescue piritramide, as sufficient to achieve optimal post-caesarean section analgesia. Achieving NRS $\leq 4$ might not have been good enough for all of these parturients, and there was no upper limit to the rescue piritramide dose at any time. Functional recovery is maybe the most important issue after caesarean section.

During the study period, the Department policy for obstetric spinal anaesthesia was changed from $0.5 \%$ levobupivacaine to $0.5 \%$ hyperbaric bupivacaine. The study protocol was not changed, but the spinal anaesthesia block was seen to be less successful with levobupivacaine in this study (i.e., anaesthesia not deep enough, or block not great enough for surgery). Indeed, nine (15.3\%) of the parturients needed supplemental analgesics and/or general anaesthesia, as most of them reached a block to only $\mathrm{TH}_{6}$, and one for the extended operation. All of these parturients were included in the analysis, as this situation did not activate any of the specified exclusion criteria.

However, the parturient numbers that were reached here were not as many as initially defined in the sample size calculation, as the study was terminated early for ethical reasons (i.e., not to expose our parturients to any unnecessary pain or/and general anaesthesia). Thus, an important limitation here is that our study was terminated early, with smaller numbers of parturients included. Indeed, this might have been the causal factor for the significant differences in the parturient characteristics concerning age and gestational age, between the LB group and the placebo group. Therefore this study can be considered as a pilot study.

Also at this stage, the ideal effective dose of ketorolac for addition to local anaesthetics for in-wound infusion is not known. Further studies are needed to evaluate the full clinical advantages of ketorolac added to a local anaesthetic for in-wound infusion for post-caesarean section analgesia.

To the best of our knowledge, the present study is the first trial to investigate the efficacy of over-fascia continuous in-wound infusion of a local anaesthetics and a NSAID separately and in combination, in comparison to saline placebo. Based on these data, ketorolac alone and in combination with a local anaesthetic as in-wound infusion are the most effective for reduction of post-operative consumption of piritramide. The novelty of our study lies in our data for successful post-caesarean section analgesia with a combination of a local anaesthetic and a NSAID for over-the-fascia in-wound infusion.

\section{Conclusion}

The present study indicates that local infiltration of a NSAID alone or in combination with a local anaesthetic have superior efficacy over a local anaesthetic alone for reduction of opioid consumption during post-caesarean section analgesia.

\section{Abbreviations \\ ASA: American Society of Anesthesiologists; Cl: confidence interval; CONSORT: Consolidated Standards of Reporting Trials; i.v.: intravenously; KT: ketorolac tromethamine; LB: levobupivacaine; NRS: numeric rating scale; NSAID: non-steroidal anti-inflammatory drug; SD: standard deviation; $\mathrm{SpO}_{2}$ : peripheral oxygen saturation pressure}

Acknowledgements

Not applicable.

Funding

None.

Availability of data and materials

Reasonable requests for access to the datasets used and/or analysed during this study can be made to the corresponding author. 


\section{Authors' contributions}

JWK was involved in designing the study, collecting and interpretation of data, and drafting the manuscript. PPB carried out the statistical analysis, and was involved in interpretation of data and drafting the manuscript. DM conceived and designed the study, and was involved in interpretation of data and drafting the manuscript. All of the authors critically revised and approved the final form of the manuscript.

\section{Ethics approval and consent to participate}

This study was approved by the National Medical Ethics Committee (Republic of Slovenia National Medical Ethics Committee, Number 169/07/11) on July 12, 2011. All of the participants gave their written, informed consent to participate in the study.

\section{Consent for publication}

Not applicable.

\section{Competing interests}

The authors declare that they have no competing interests.

\section{Publisher's Note}

Springer Nature remains neutral with regard to jurisdictional claims in published maps and institutional affiliations.

\section{Author details}

'Department of Anaesthesiology, Intensive Care and Pain Management, University Medical Centre Maribor, Ljubljanska ulica 5, 2000 Maribor, Slovenia. ${ }^{2}$ Faculty for Health Sciences, University of Maribor, Žitna ulica 15, 2000 Maribor, Slovenia. ${ }^{3}$ Medical Faculty, University of Maribor, Taborska ulica 8, 2000 Maribor, Slovenia. ${ }^{4}$ Faculty of Electrical Engineering and Computer Science, University of Maribor, Koroška cesta 46, 2000 Maribor, Slovenia. ${ }^{5}$ Department for Medical Research, University Medical Centre Maribor, Ljubljanska ulica 5, 2000 Maribor, Slovenia.

\section{Received: 27 April 2018 Accepted: 5 October 2018}

\section{Published online: 10 November 2018}

\section{References}

1. Gibbons L, Belizan JM, Lauer JA, Betran AP, Merialdi M, Althabe F. The Global Numbers and Costs of Additionally Needed and Unnecessary Caesarean Sections Performed per Year: Overuse as a Barrier to Universal Coverage. World Health Report (2010), Background Paper 30. Geneva: World Health Organization; 2010.

2. OECD. Caesarean sections, in health at a glance 2015: OECD indicators, OECD publishing. Paris: DOl; 2015. https://doi.org/10.1787/health-data-en. (accessed 4 May 2017

3. Gerbershagen HJ, Aduckathil S, van Wijck AJM, Peelen LM, Kalkman C Meissner W. Pain intensity on the first day after surgery: a prospective cohort study comparing 179 surgical procedures. Anesthesiology. 2013;118(4):934-44.

4. Sinatra R. Causes and consequences of inadequate management of acute pain. Pain Med. 2010;11:1859-71.

5. Eisenach JC, Pan PH, Smiley R, Lavand'homme P, Landau R, Houle TT. Severity of acute pain after childbirth, but not type of delivery, predicts persistent pain and postpartum depresssion. Pain. 2008;140:87-94.

6. Nikolajsen L, Sorensen HC, Jensen TS, Kehlet H. Chronic pain following caesarean section. Acta Anaesth Scand. 2004:48:111-6.

7. Eisenach JC, Pan P, Smiley RM, Lavand'homme P, Landau R, Houle TT. Resolution of pain after childbirth. Anesthesiology. 2013;118:143-51.

8. Wong CA, McCarthy RJ, Blouin J, Landau R. Observational study of the effect of $\mu$-opioid receptor genetic polymorphism on intrathecal opioid labor analgesia and post-caesarean delivery analgesia. Int J Obstet Anesth. 2010;19:246-53.

9. Landau R, Kraft JC. Pharmacogenetics in obstetric anaesthesia. Curr Opin Anaesthesiol. 2010;23:323-9.

10. Pan PH, Tonidandel AM, Aschenbrenner CA, Houle TT, Harris LC, Eisenach $J C$. Predicting acute pain after caesarean delivery using three simple questions. Anesthesiology. 2013;118:1170-9.

11. Tan M. Post caesarean analgesia. Trends Anaesth Crit Care. 2012;2:128-32.

12. Bamigboye AA, Hofmeyr GJ. Local anaesthetic wound infiltration and abdominal nerve block during caesarean section for postoperative pain relief. Cochrane Database Syst Rev. 2009;8:CD006954.
13. Kehlet H, Liu SS. Continuous local anesthetic wound infusion to improve postoperative outcome. Back to the periphery? Anesthesiology. 2007:107:369-71.

14. Scott NB. Wound infiltration for surgery. Anaesthesia. 2010;65:67-75.

15. Carvalho $B$, Lemmens HJ, Ting $\vee$, et al. Postoperative subcutaneous instillation of low-dose ketorolac but not hydromorphone reduces wound exudate concentrations of interleukin- 6 and interleukin-10 and improves analgesia following cesarean delivery. J Pain. 2013;14(1):48-56.

16. Lavand'homme PM, Roelants F, Waterloos H, De Kock MF. Postoperative analgesic effect of continuous wound infiltration with diclofenac after elective cesarean delivery. Anesthesiology. 2007;106:1220-5.

17. Rackelboom T, Le Strat S, Silvera S, et al. Improving continuous wound infusion effectivness for postoperative analgesia after caesarean delivery: a randomized controlled trial. Obstet Gynecol. 2010;116:893-900.

18. Kainu JP, Sarvela J, Halonen P, et al. Continuous wound infusion with ropivacaine fails to provide adequate analgesia after caesarean section. Int J Obstet Anesth. 2012;21:199-24.

19. Lalmand M, Wilwerth M, Fils JF, et al. Continuous ropivacaine subfascial wound infusion compared with intrathecal morphine for postcesarean analgesia: a prospective, randomized controlled, double-blind study. Anesth Analg. 2017;125(3):907-12.

20. Jolly C, Jathières F, Keïta $H$, Jaouen E, Guyot B, Torre A. Cesarean analgesia using levobupivacaine continuous wound infiltration: a randomized trial. Eur J Obstet Gynecol Reprod Biol. 2015;194:125-30.

21. O'Neil P, Duarte F, Ribeiro I, et al. Ropivacaine continuous wound infusion versus epidural morphine for postoperative analgesia after caesarean delivery: a randomized controlled trial. Anesth Analg. 2012;114:179-85.

22. Adesope O, Ituk U, Habib AS. Local anaesthetic wound infiltration for postcaesarean section analgesia: a systematic review and meta-analysis. Eur J Anesth. 2016;33(10):731-42.

23. Vacha ME, Huang W, Mando-Vandrick J. The role of subcutaneous ketorolac for pain management. Hosp Pharm. 2015;50(2):108-12. https://doi.org/10. 1310/hpj5002-108.

24. Burdick M, Mamelok R, Hurliman M, et al. Comparison of the pharmacokinetics of ketorolac tromethamine after continuous subcutaneous infusion and repeat intramuscular bolus injections in healthy adult subjects. Clin Pharmacol Drug Developm. 2017;6(4):343-9.
Ready to submit your research? Choose BMC and benefit from:

- fast, convenient online submission

- thorough peer review by experienced researchers in your field

- rapid publication on acceptance

- support for research data, including large and complex data types

- gold Open Access which fosters wider collaboration and increased citations

- maximum visibility for your research: over $100 \mathrm{M}$ website views per year

At $\mathrm{BMC}$, research is always in progress.

Learn more biomedcentral.com/submissions 